\title{
Integrating Public Health into Local Healthcare Governance in Quebec: Challenges in Combining Population and Organization Perspectives
}

\section{L'intégration de la santé publique à la gouverne locale des soins de santé au Québec : enjeux de la rencontre des missions populationnelle et organisationnelle}

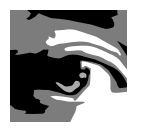 \\ by MYLAINE BRETON, MBA \\ University of Montreal, Montreal, QC \\ JEAN-FRÉDÉRIC LÉVESQUE, MD, PHD \\ Institut national de santé publique et Centre de recherche du \\ Centre hospitalier de l'Université de Montréal (CRCHUM) \\ Montreal, QC \\ RAYNALD PINEAULT, MD, PHD \\ Institut national de santé publique, Montreal, QC
}

LISE LAMOTHE, PHD

University of Montreal, Montreal, QC

JEAN-LOUIS DENIS, PHD

University of Montreal, Montreal, QC 


\section{Abstract}

The quest for greater efficiency in health systems encourages governments to bring together two fields of practice that have largely developed in parallel in industrialized countries: public health and healthcare. Current healthcare reform in the province of Quebec formally integrates these two fields within a common governance structure. The objective of this paper is to discuss the issues arising from the integration of public health services into the planning and delivery of local healthcare services, and its potential effect on the overall performance of the healthcare system. The authors begin by describing the characteristics of these two sectors; then, they discuss current reforms in Quebec and the impact of various transitions (epidemiological, technological and organizational) that bring the sectors into greater convergence. The paper concludes with a discussion of obstacles and potential opportunities at two levels: (a) the development of population-based planning of services within healthcare organizations, and (b) the articulation of public health and healthcare services concerns at the local level. The ongoing reform in Quebec is a unique opportunity to maximize outcomes from the resources invested in the healthcare system, based on a collective vision for improving health.

This paper was originally published in French, in the journal Pratiques et organisation des soins 39(2): 113-24.

\section{Résumé}

La recherche d'une plus grande efficience du système de santé incite les gouvernements à rapprocher deux domaines d'activités du secteur de la santé qui se sont largement développés en parallèle dans les pays industrialisés : la santé publique et le système de soins. La réforme en cours au Québec intègre plus formellement ces deux domaines de prestations au sein d'une même gouverne institutionnelle. L'objectif de cet article est de discuter des enjeux découlant de l'intégration formelle de la santé publique au niveau de la planification et de la prestation de soins locaux et de son potentiel pour la performance d'ensemble du système de santé. En premier lieu, nous présentons les caractéristiques de ces deux domaines de prestation du système de santé : la santé publique et le système de soins. Nous expliquons ensuite la réforme en cours au Québec et discutons des transitions épidémiologiques, technologiques et organisationnelles qui amènent une plus grande convergence entre ces deux domaines. Nous terminons par une discussion des obstacles et opportunités potentielles de cette réforme. Nous discutons de ces défis selon deux niveaux soit : (a) le développement d'une planification populationnelle à l'intérieur d'organisation de prestation de soins et services et (b) l'articulation de préoccupations de santé publique et de système de soins à un niveau local. La réforme en cours au Québec est une occasion unique pour maximiser l'impact des ressources investies dans le système de soins selon une vision collective d'amélioration de la santé.

Article publié en français dans la revue Pratiques et organisation des soins 39(2): $113-24$. 


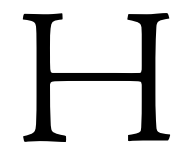

EALTH SYSTEMS IN INDUSTRIALIZED COUNTRIES ARE CURRENTLY undergoing significant transformations. These changes are largely due to the influence of demographic and epidemiological transitions associated with aging populations and a steady increase in the social and economic burden of chronic diseases. In addition, technological and pharmacological advances have increased the health system's capacity for intervention. Governments are looking into ways to improve the organization and management of health services to augment the impact of collective resources invested in the health of the populations served. This examination has been accompanied by a re-evaluation of the performance of health systems and the implementation of reforms, the scope of which varies in each country.

In the Canadian context, a number of committees have reviewed the state of provincial health systems (Romanow 2002; Kirby 2002; Clair 2000). Overall, a consensus is emerging concerning the lack of preventive action, problems of access to care (especially first contact), lack of coordination and ineffective use of healthcare providers. These working groups have suggested necessary changes or innovations, and provincial governments have launched a significant series of reforms. Quebec has not escaped this trend. Since its inception over 40 years ago, the public healthcare system has undergone a number of changes, influenced by successive waves of reforms (Lévesque et al. 2007b).

A characteristic of these reforms is the gradual integration of public health resources, defined as a sector that includes collective health interventions, into healthcare, which, in contrast, is concerned with preventive, diagnostic, curative and rehabilitative interventions at the individual level. Although these reforms have been well received by various stakeholders, issues still remain regarding the true contribution of one sector to the activities of the other. Some studies have described the difficulties associated with the integration of services with somewhat contradictory objectives (Beaglehole and Bonita 1998). Moreover, previous efforts to integrate public health into the healthcare system, through the introduction of community health departments into hospitals, have had limited success in Quebec (Pineault et al. 1990).

The objective of this paper is to discuss issues arising from the formal integration of public health services into the planning and delivery of local healthcare services, and the potential effects on the overall performance of the health system. We first introduce the two sectors: public health and healthcare. We then describe current reforms in Quebec and discuss the impact of various transitions (epidemiological, technological and organizational) that bring these two sectors into greater convergence. We conclude with a discussion of the potential obstacles to, and opportunities of, reform at two levels: development of population-based planning within organizations involved in the delivery of healthcare, and expression of public health and healthcare services concerns at the local level. The ongoing reform in Quebec provides a unique opportunity to maximize the impact of resources invested in the healthcare system, based on a collective vision for improving health. 


\section{Individual and Collective Services: Two Areas of Service Delivery in the Health Sector}

The World Health Organization (WHO) has identified two areas of service delivery that enable health systems to meet the health needs of populations: personal services, which include preventive, diagnostic, therapeutic, rehabilitative and palliative care services consumed by the individual, and collective or non-personal services, which consist of health promotion and disease prevention activities targeted to groups within the population (Murray and Frenk 2000). According to this view, public health and healthcare delivery coexist within the health system, but functional interactions between these two sectors vary from country to country. Traditionally, public health interventions are seldom integrated into the healthcare system. In this section, we will define the public health and healthcare sectors and describe their key functions, the actors involved and their intervention goals and methods.

\section{Public health: provision of collective services}

Public health is defined as "the science and art of preventing disease, prolonging life and promoting health through the organized efforts of society" (Acheson 1998). Such collective efforts are not limited to specific services or programs. The current trend in Western countries is to adopt a comprehensive definition of public health and advocate for "organized efforts of society" likely to have an impact on human health in the broadest sense (e.g., speed limits on roads, access to a minimum income) (Colin 2004).

In Quebec, collective action is carried out through a series of functions devolved from public health that cover a wide range of interventions. The province's public health program includes such functions as (1) surveillance and analysis of the population's health and well-being status and its determinants; (2) health protection and the control of risks and diseases (infectious diseases, injuries and social problems); (3) prevention of diseases, injuries and social problems (suicide, violence, substance abuse); (4) promotion of health and well-being; (5) drafting of regulations, legislation and public policies that have an impact on health; (6) research and innovation, including production, dissemination and application of scientific knowledge; and (7) skills development and maintenance (Ministère de la santé et des services sociaux 2003).

A number of studies have demonstrated significant differences in life expectancy among individuals within a population. The health of individuals is influenced by many factors such as social position, level of education and occupation (Contandriopoulos 1999; Contandriopoulos et al. 2000; Evans 1999; Marmot et al. 1997). Personal lifestyle habits, especially smoking and alcohol use, diet and physical activity also influence health and well-being (Klein-Geltink et al. 2006; Ohinmaa et al. 2006). For example, some studies estimate that in Canada, smoking is responsible for at least one-quarter of all deaths in adults aged 35 to 84 (PHAC 2005). There is 
growing recognition that lifestyle habits are largely influenced by the socio-economic environments in which people live.

Progress in understanding health determinants has led many researchers to develop "population health" models that attempt to comprehend the interactions among these various determinants (Evans and Stoddart 1990; Glouberman and Minzberg 2002). Health results from multiple determinants, none of which is an absolute determinant. For example, unemployment can cause social isolation and poverty, which then affect an individual's psychological health and capacity to adapt. Moreover, factors that influence the health of individuals are not necessarily the same as those influencing the health of the population, because health determinants act on both the individual and the collective levels. This notion is congruent with Rose's (1985) observation that "the causes of individual cases are not the same as the causes of overall incidence."

Public health adopts a comprehensive perspective, focusing its actions on many health determinants to improve and maintain population health and well-being (Glouberman and Millar 2003; McKeown 1979; WHO 1986). While this perspective includes healthcare delivery in determinants of health, it is not restricted to this activity and has traditionally allocated it limited space. In this view, healthcare has a limited impact on population health compared to other determinants such as lifestyle habits.

Public health interventions are broad and involve prevention, promotion and protection. Disease prevention includes risk reduction and refers to interventions whose goal is to forestall an event or particular health condition. This approach targets individuals and groups that exhibit identifiable risk factors, focusing mainly on disease. Health promotion falls more within group dynamics, where the goal is the health and well-being of the population (Lévesque and Déry 2001). Health promotion interventions not only target changes in individual characteristics; they are now also based on an ecological approach that combines organizational, community and political initiatives (Richard et al. 1999).

\section{Healthcare delivery: provision of individual services}

Care provision involves a relationship between a person who has a health problem and various care providers. Resources are mobilized within this framework to modify or maintain the person's state of health (Donabedian 1976). Various medical investigations and therapies are deployed to solve a given health problem. The health system's key functions are to restore a state of non-illness, prevent the deterioration of health status and preserve a person's autonomy. Therefore, healthcare interventions are centred around maintaining health or restoring absence of disease, perceived here as any poor biological functioning that appears as quantitative disturbances of physiological phenomena (Canguilhem 1966). To solve a health problem, the cause must be identified and eliminated, or its symptoms corrected with an appropriate medical 
intervention. Most healthcare interventions are curative and target individuals, not populations. Intervention strategies are more often directed towards diagnosis, treatment, rehabilitation or palliative care. Most interventions are performed in healthcare facilities.

The healthcare sector is composed of resources (professional, institutional and others) structured to provide goods and services to the population, with a goal of improving health (Pineault and Lessard 1984). Its main concern is to meet the demands of individuals seeking care. It involves planning according to supply and demand: production varies based on demand, and demand is influenced by effective supply of services. Healthcare services are managed according to the logics of management and administration (Pineault and Daveluy 1995). The organizational perspective is dominant. Historically, this planning of services has mainly targeted users. Thus, the needs of non-users have traditionally been inadequately considered, and populationbased planning has not been prominent.

\section{Organization of Quebec's healthcare system: Parallels and bridges}

Public health and healthcare are often perceived as opposing rather than interrelated fields (Bergeron and Gagnon 2003). Over the last few decades, the context in which the two sectors operate has changed. Influenced by pressures from several fronts, they have converged to a greater degree (Figure 1). They are naturally growing closer, with each sector needing the expertise the other can provide to address complex health problems such as chronic diseases (Bergeron and Gaumer 2007). In the following section, we discuss the various transitional factors that have allowed greater convergence between these two service delivery areas.

FIGURE 1. Convergence between public health and healthcare

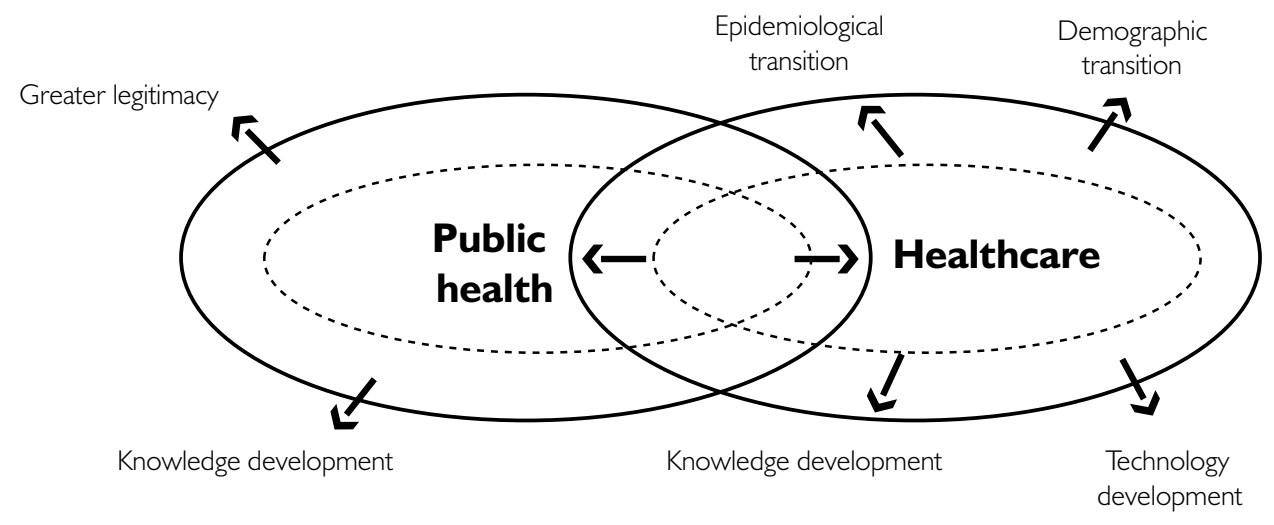


Subsequent to several successive reforms in Quebec, public health was formally institutionalized at various hierarchical levels of the governance structure. Figure 2 presents a brief history of how governance structures in Quebec have evolved.

FIGURE 2. Evolution of the health system's governance structures in Quebec

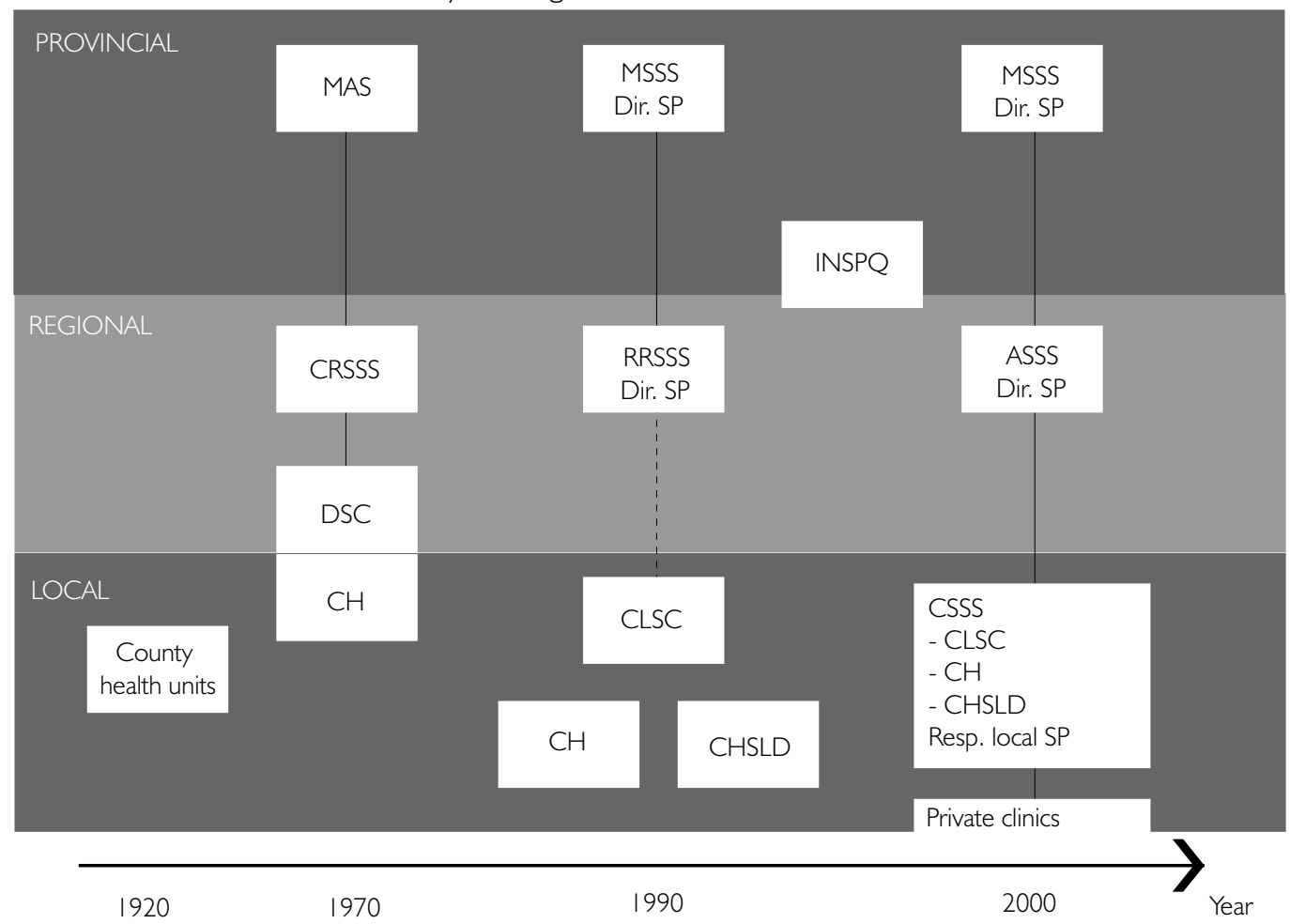

MAS: Ministère des affaires sociales (Department of Social Affairs)

CRSSS: Conseil régional de santé et de services sociaux (Regional Health And Social Services Council)

DSC: Département de santé communautaire (Department of Community Health)

$\mathrm{CH}$ : Centre hospitalier (hospital centre)

MSSS: Ministère de la santé et des services sociaux (Ministry of Health and Social Services)

SP: Santé publique (public health)

RRSSS: Régie régionale de la santé et des services sociaux (Regional Health and Social Services Boards)

CLSC: Centre local de services communautaires (Local Community Services Centre)

CHSLD: Centre hospitalier de soins de longue durée (long-term care facility)

INSPQ : Institut national de santé publique du Québec

ASSS: Agence de santé et de services sociaux (health and social services agency)

CSSS: Centre de santé et des services sociaux (health and social services centre)

The first public health institutions appeared during the 1920s with the implementation of county health units (unités sanitaires de comté). Their principal activities were education for pregnant women, young mothers and school-aged children, infectious disease control, sanitation and collection of demographic data (Bergeron and Gagnon 2003).

Then, following the recommendations of the Castonguay-Nepveu Commission, Quebec adopted the Health Insurance Act and undertook a broad restructuring opera- 
tion. The Department of Social Affairs was created as a result of the changes carried out in the 1970s. Moreover, 12 regional health and social services councils (Conseils régionals de santé et de services sociaux, or CRSSS) were implemented and given an advisory mandate; hospital centres under separate administrative management were also implemented, and local community services centres were proposed to dispense both health and social services (Bergeron and Gagnon 2003). In 1974, 32 community health departments (Départements de santé communautaire, or DSC) were created. Their mission was to assume responsibility for public health in their designated territories and to take action regarding preventive interventions in their host hospitals. DSC seemed to be a solution to the integration of public health functions within hospitals (Bergeron and Gagnon 2003). Given the central place accorded to hospitals in the system, their responsibilities and the size of the populations they served, these institutions seemed to be the best place to bring public health closer to curative services. However, the DSC did not meet this objective because the integration of curative and preventive services did not occur. On the contrary, the presence of public health departments in the hospitals took the responsibility for prevention away from the other professionals (Pineault 1984; Pineault et al. 1986).

In the 1990s, the health system was reorganized once again, with an Act Respecting Health Services and Social Services, enacted in 1991. In 1992, the Ministry of Health established a public health branch within its own department. In addition, the Quebec government set up regional health and social services boards (Régies régionales de la santé et des services sociaux, or RRSSS). Their mandate was to coordinate service delivery in their regions and to allocate resources to institutions and community organizations in their territories. The provincial government also delegated to RRSSS the task of managing regional public health programs and creating public health departments (Bergeron and Gagnon 2003). During this period, the government undertook a vast operation to merge institutions, reducing the number of public establishments from 1,000 to about 500 (Turgeon et al. 2003).

At the end of the 1990s, in addition to having separate provincial and regional public health departments, a provincial public health institute (Institut national de santé publique du Québec, or INSPQ) was created. The Quebec government aimed to consolidate and develop public health expertise and especially to make this expertise, which was concentrated in regions where universities are located, accessible to all regions of the province (Bernier 2006).

In 2003, the Quebec government once again undertook a major reorganization of its health network. Regional boards were renamed health and social services agencies (Agences de santé et de services sociaux, or ASSS), and their mandate was redefined to support the development of local services networks on a geographic basis while continuing to allocate funds to establishments in their regions. Moreover, the Quebec government added a local level to the formal integration of public health into deci- 
sion-making structures. Although local community service centres (Centres locaux de services communautaires, or CLSCs) were partly responsible for providing the bulk of direct services to the population on a local level (Lévesque and Bergeron 2003b), the new reform added a further responsibility to develop local public health plans. In Quebec, the recent reorganization has introduced the mandate of population-based responsibility to a new health organization, the Centre de santé et des services sociaux (CSSS), created as a result of merging long-term care facilities, CLSCs and, in most cases, a hospital centre (Gouvernement du Québec 2003). The objective was to confer to the 95 CSSSs the responsibility of developing services adapted to the needs of a geographically defined population. CSSSs are responsible for creating and piloting local intersectoral collaborations, with a view towards acting on health determinants and improving service delivery to the population. Moreover, a local officer in charge of public health is appointed in each CSSS. By introducing these local institutions, the Quebec government has formally integrated public health into local governance structures (Bergeron and Gaumer 2007). Assignment of a dual responsibility (delivery of care and services, and public health) to CSSSs requires broadening service provision by adopting a population-based plan and integrating public health into its activities.

Attempts have been made on an international level to articulate public health and healthcare issues in a more formal manner within a single governance structure. For instance, several countries have drawn inspiration from Kaiser Permanente's clinical model, cited as a successful innovative model that integrates clinical prevention into the production of high-quality care at the best cost (Feachem et al. 2002; Ham et al. 2003). Another example is the Veterans Health Administration, the largest integrated public healthcare system in the United States (Kizer et al. 2000; Perlin et al. 2005). Its new organizational model is centred around patients, and is coordinated according to different levels of care within delimited geographical areas (Kizer et al. 2000). The VHA is interesting because it is an example of a shift from a system governed by a hospital-centred model to non-institutional care. The Finnish healthcare and services organizational model comes closest to a community care model (Lamarche et al. 2003). In that country, municipalities are responsible for the provision of healthcare services to the population (Ministry of Social Affairs and Health Finland 2004). These examples illustrate models that have succeeded in integrating both perspectives to varying degrees.

\section{Towards Greater Convergence between Public Health and Healthcare Services}

In several countries, public health and healthcare have evolved in parallel, with little interaction (Lévesque et al. 2003b). Influenced by pressures from several sources, in Quebec these two sectors tend to be closer despite often divergent perspectives. In this 
section, we discuss three transitions that seem to influence this convergence: the epidemiological transition, the technological transition and the organizational transition. We also examine the challenges to integrating public health and healthcare services.

\section{Epidemiological transition}

In industrialized countries, the profile of major causes of disease and death has changed significantly over the past few decades (McMichael and Beaglehole 2000). Chronic diseases are now the principal cause of morbidity and mortality worldwide (WHO 2005); as such, they have become priority issues for healthcare systems. Almost $40 \%$ of adults in industrialized countries are at risk for reported chronic health conditions such as diabetes, hypercholesterolemia, hypertension, respiratory disease, heart disease or circulatory pathology (Broemeling et al. 2005; Starfield et al. 2003). Thus, these conditions have become priority issues for healthcare systems in many countries, as they represent a significant societal burden and are largely preventable (McMichael and Beaglehole 2000; Birmingham et al. 1999; Katzmarzyk et al. 2000).

An epidemiological transition changes the nature of health problems that public health and healthcare sectors have to address. First, for people living with chronic diseases, health promotion also includes services that help them live better with their disease. Moreover, prevention is increasingly carried out through clinical screening programs. Prevention and treatment of health problems are no longer the sole prerogatives of a specific sector. Screening and health promotion in clinical settings, through promotion of self-care, are conducted on an individual basis and work towards treatment as well as health promotion among people with chronic diseases.

\section{Technological transition}

Technological and scientific advances are making rapid headway. An increase in diagnostic capacities, ongoing development of investigative technologies (e.g., radiography), pharmacotherapy (e.g., antibiotics) and biochemistry (e.g., anaesthesia) allow for effective treatment of an ever-growing number of diseases; they also enable more and longer interventions for each individual (Contandriopoulos 2003). These include increasingly sophisticated techniques for resuscitation, organ transplantation and medically assisted reproduction, and developments in medical imaging (Champagne et al. 2004). Moreover, recent advances in technology are making it possible to focus more on disease screening and prevention. Examples of these advances include hypertension treatments that lower the incidence of stroke, Pap smears that reduce cervical cancers and polyp removal during colonoscopy (Sicard 2004).

Among recent technological developments, it is clear that the mapping of the 
human genome and advances in gene therapy will have an impact not only on public health practice but also on curative medicine and health services management. Indeed, identification of susceptibility genes will improve the targeting of public health interventions. The resulting screening activities will affect costs and raise ethical issues (Collins 1999).

\section{Organizational transition}

The higher prevalence of chronic diseases and the complexity of patients' needs require a variety of health services as well as concerted action by health professionals and other stakeholders. These clienteles require regular and more intensive contacts with various providers and interventions that are better coordinated. They need better integrated care and continuity among different service delivery sites. Services organization is complex and covers a broad spectrum of intervention that ranges from preventive services to treatment, and from follow-up to convalescence. Change in patient management logically leads to network-based organization, and new organizational models add complexity to healthcare processes.

High-performance health systems are those in which information concerning prevalent health problems is available and utilized, where preventive interventions are planned across the continuum of care delivery and where care provision is a source of health promotion. Increasingly, healthcare interventions must be planned according to their impacts on targeted populations. The era is past when all that was required was to offer the best treatment available on an individual basis. Public health methods and expertise are needed for such population-based planning.

\section{Challenges and issues}

Although recent reforms have facilitated greater convergence between public health and healthcare in Quebec, these two sectors are driven by relatively distinct visions that are even contradictory in some areas. For instance, when it comes to interventions, public health is interested in the population as a whole, whereas healthcare targets individuals. Moreover, the interventions' temporal scales are different. The results of environmental interventions may not become apparent for years; on the contrary, if the intention is immediate reduction of pain or anxiety caused by disease, results are easy to observe in the short term and the causal relationships are more direct. Table 1 presents a summary of the various tensions between these two areas of service delivery.

Such tensions create significant challenges regarding the formal integration of public health into local governance structures. We will discuss these challenges on two levels: (a) the development of population-based planning within organizations that 
deliver healthcare services and (b) the expression of public health and healthcare concerns at the local level.

TABLE 1. Tensions between public health and healthcare

\begin{tabular}{|c|c|c|}
\hline Public health & Delivery & Healthcare system \\
\hline $\begin{array}{l}\text { Population in the territory that uses or } \\
\text { does not use the services }\end{array}$ & Target & Individuals who use the services \\
\hline $\begin{array}{l}\text { Improve the health of the population of } \\
\text { the territory, over the medium and long } \\
\text { terms }\end{array}$ & Objectives & $\begin{array}{l}\text { Improve the health of individuals who use } \\
\text { care, at the time they need it }\end{array}$ \\
\hline $\begin{array}{l}\text { Focus on prevention, promotion and } \\
\text { protection }\end{array}$ & Services offered & Focus on diagnostic and curative services \\
\hline $\begin{array}{l}\text { Public health professionals and various } \\
\text { intersectoral stakeholders }\end{array}$ & Stakeholders concerned & $\begin{array}{l}\text { Healthcare professionals and } \\
\text { administrators }\end{array}$ \\
\hline Forward-looking, anticipates problems & Temporality & Corrects the past, reacts to problems \\
\hline $\begin{array}{l}\text { Numerator/denominator relationships, } \\
\text { population-based effectiveness }\end{array}$ & Types of effectiveness & $\begin{array}{l}\text { Interested in the numerator, clinical } \\
\text { effectiveness and use }\end{array}$ \\
\hline
\end{tabular}

Source: Agence de santé et de services sociaux de Montréal, 2004 (as adapted by Derose and Petitti 2003; Garr et al. 1993).

\section{POPULATION-BASED PLANNING WITHIN ORGANIZATIONS THAT DELIVER}

The assignment of geographically defined population responsibility to Health and Social Services Centres (CSSSs) undoubtedly poses new challenges. We will look at three issues that complicate population-based planning within healthcare and services delivery organizations: changes in the planning process from individual-level to community-level planning; service planning based on foreseeable needs; and critical-mass planning.

One of the first issues is to change the planning process from one based on delivery of individual services to one geared towards community-based planning. This new mandate introduces the notion of territory into the planning process. Planning must not only respond to the needs of service users but also consider the needs of individuals or groups who, for a variety of reasons, do not currently consult healthcare providers to meet their needs. This view differs from traditional management of organizations, which is based on response to service demands. Such an exercise in planning is more complex in urban areas, where an organization's catchment area may not correspond to geographical territories and where individuals living in different neighbourhoods sometimes use services located far from where they reside.

According to Pineault and Daveluy (1995), applying a purely population-based perspective to planning is naive and ineffective because it does not take into con- 
sideration organizational reality, that is, the existing complement of resources, their organization and accompanying constraints. The most appropriate model is a compromise between a population-based and an organizational planning process (based on users and resources). The challenge is to build on available resources in the territory to increase the impact on population health. Therefore, within the context of such reform, administrators are compelled to think not only about clinical effectiveness linked to service utilization, but also and especially about population-based effectiveness, because administrators have to know whether the resources that have been mobilized are producing the expected outcomes within the community.

Apart from discussions regarding the resources invested in these respective fields of delivery, almost all of the budget should be invested based on a collective vision for health improvement. Resources should be geared towards achieving greater population-based effectiveness through healthcare. Indeed, by promoting a population-based approach, public health encourages the healthcare sector to strive for such effectiveness. In this regard, the healthcare sector constitutes a powerful medium for prevention efforts because of the significant percentage of individuals who use services during a year (close to $75 \%$ ), especially primary care services, and because the situations of these clients (and their loved ones) often make them particularly sensitive to prevention efforts, including counselling. Clinical prevention is an example of a growing, population-based, effective response to non-expressed needs.

Second, the current health system was designed to address acute problems in a timely fashion. However, an epidemiological transition - change in the epidemiological profile to a greater prevalence of chronic diseases - has a significant impact on the nature of health problems faced by the healthcare sector. Chronic diseases evolve in a more predictable fashion than do acute diseases; at the same time, their evolution can be altered by prevention efforts whose objectives are to maintain autonomy and quality of life while respecting human dignity (e.g., palliative care). This approach ensures that services are planned in a more predictable and sequential manner. For instance, having 4,000 diabetics within a territory enables an organization to plan 4,000 consultations in ophthalmology for the upcoming year.

Finally, integrating public health into CSSSs can change the logic of services planning at the local level. But are CSSSs the right vehicles for integration? CSSS have close relationships with at most $30 \%$ of the population that uses such services as consultations, hospitalizations or services in CLSCs (Lévesque et al. 2007b). As a result, on an annual basis, CSSSs fail to reach several clienteles that receive most of their services in privately run clinics. If local services networks ${ }^{1}$ are not implemented, CSSSs will have difficulty reaching the population. CSSSs also face several challenges in developing partnerships with service providers in their territories. A promising avenue is to develop business relationships with primary care medical organizations within a territory, an approach that would facilitate managing the territory's population. Indeed, almost $65 \%$ 
of the population obtain health services mostly from private physicians' offices. ${ }^{2}$

In summary, the integration of population-based planning into healthcare and services delivery can represent a major challenge. There is still a risk of confrontation between public health and healthcare logistics. Mediating between response to the needs of individuals who arrive at organizations and complementary identification of non-expressed needs can be difficult in a context where resources are limited. Nonetheless, these various issues can be surmounted and should be taken into account to ensure the success of this reform of public health and health services organization.

ARTICULATION OF PUBLIC HEALTH AND HEALTHCARE SERVICES CONCERNS AT THE LOCAL LEVEL

Integrating key public health concerns with issues related to care and services delivery is not necessarily obvious or natural. We will look at the difficulties in terms of two fundamental differences: the limits of each sector and their respective targets.

Although the current context fosters convergence between the two services delivery areas regarding preventive clinical practices, screening and selection of interventions based on the needs of the population, some public health interventions remain outside the healthcare domain. Public health is interested in much broader and more diversified areas that are not covered under healthcare, such as the environment, public infrastructures and occupational safety. Public health may therefore receive short shrift in an organizational structure where healthcare delivery is the central concern. So is it appropriate to integrate public health into organizations that provide healthcare services? We might have reservations about such an approach, because many public health initiatives are macroscopic in nature and the local level has relatively little control and leverage to act.

Local integration contrasts with a much more comprehensive view of the scope of public health intervention to influence population health. In this context, one public health issue is to better define the limits of its interventions within the health system. Healthcare delivery is an excellent venue - complementing more traditional intervention methods - in which to conduct public health interventions. For example, Montreal's public health department implemented health education centres in various CSSSs in the region. These CSSSs sought to improve three lifestyle habits that have an impact on chronic diseases - smoking, exercise and diet. This strategy supplemented and supported preventive clinical practices in private and public medical clinics in their territories.

Second, the main targets of both sectors often pull in opposite directions, creating conflicts that are difficult to overcome. The rationale behind clinicians' and organizations' search for solutions is to maximize individual services by advocating for their patients to obtain the best possible interventions. However, the rationale guiding public health is to maximize health for the population as a whole. This population-based 
perspective affects large groups of individuals; its goal is to ensure mediation on a population scale. These differences could be difficult to reconcile in the context of healthcare delivery at the local level. This paradox will always exist; it reflects the realities of services delivery and could reduce the reach of public health interventions carried out by the healthcare sector.

Moreover, both these domains of intervention should be articulated on a local level. Beyond one-off interventions with individuals who consult healthcare providers, interventions with groups and with healthcare organizational methods can enhance the impact of services on the health of the population. Diabetes is a good example of the links between individual- and population-based approaches. Interventions at different levels across the health continuum can be implemented, for instance to avoid complications among diabetics using a health management model, to prevent diabetes among people at risk through screening and counselling interventions, and to promote healthy lifestyle habits in the population through educational and environmental strategies. CSSSs are increasingly confronted with a need to implement strategies to provide healthcare to their patients while developing strategies to prevent complications and act before symptoms appear. Interventions at different points on the health continuum enable the convergence between the public health and the healthcare sectors.

FIGURE 3. Different levels of the health continuum enabling action on diabetes

\section{Health promotion} $100 \%$ of the population

\section{Prevention}

Population at risk
Cure and care provision Population of diabetics $5 \%$ 


\section{Conclusion}

The quest for greater efficiency in health systems encourages governments to merge and integrate various activities that are likely to improve population health. The reform currently underway in Quebec presents a unique opportunity for the public health and healthcare sectors to develop more concerted and convergent activities. It has the potential to transform health services by developing services that are better adapted to the needs of the population. This strategy calls for management based on medium- and long-term visions, through building on interventions that will potentially have greater impacts on the population as a whole. Moreover, to be truly effective, such convergence must target public organizations as well as the private network, and especially primary care services, to create local services networks. It is important to direct actions not only at the organizational level but also towards the training of professionals. It would be relevant to integrate a range of possible strategies to improve population health in professional training. In our opinion, the success of reform depends on acknowledging the issues and challenges inherent in the juxtaposition of sectors that have not easily cohabited in the past. A good understanding of these issues is therefore vital.

\section{ACKNOWLEDGEMENTS}

We would like to thank Sylvie Gauthier for translating this paper.

Correspondence may be directed to: Mylaine Breton, Direction de santé publique de Montréal, 1301 Sherbrooke East, Montreal, QC H2L 1M3; e-mail: mylaine.breton@umontreal.ca.

NOTES

1. A local integrated services network is defined as providing varied and continuous services and support, treatment and rehabilitation, mostly accessible in the community and by local territory. Services are provided by a group of organizations that coordinate their efforts from a functional as well as clinical perspective.

2. Database of the project Accessibility and Continuity of Care: A Study of Primary Care Services in Québec (Pineault et al. 2008).

\section{REFERENCES}

Acheson, D. 1998. Independent Inquiry into Inequalities in Health. London, UK: HM Stationery Office.

Beaglehole, R. and R. Bonita. 1998. "Public Health at the Crossroads: Which Way Forward?" Lancet 351: 590-92. 
Bergeron, P. and F. Gagnon. 2003. “La prise en charge étatique de la santé au Québec : émergence et transformations." In V. Lemieux, P. Bergeron, C. Bégin and G. Bélanger, eds., Le Système de santé au Québec : organisation, acteurs et enjeux (pp.7-34). Saint-Nicolas: Les Presses de l'Université Laval.

Bergeron, P. and B. Gaumer. 2007."Une participation croissante de la santé publique à la gouverne du système de santé québécois ?” In M.J. Fleury, M. Tremblay, H. Nguyen and L. Bordeleau, eds., Le Système socio-sanitaire au Québec : gouvernance, régulation et participation (pp. 51-62). Montreal: Gaëtan Morin.

Bernier, N. 2006."Quebec's Approach to Population Health: An Overview of Policy Content and Organization." Journal of Public Health Policy 27: 22-37.

Birmingham, C., J. Muller, A. Palepu, J.J. Spinelli and A.H. Anis. 1999. “The Cost of Obesity in Canada." Canadian Medical Association Journal 160: 483-88.

Broemeling, A.M., D. Watson and C. Black. 2005. Chronic Conditions and Co-morbidity among Residents of British Colombia. Vancouver: Centre for Health Services and Research, University of British Columbia.

Canguilhem, G. 1966. Le Normal et le pathologique. Paris: PUF.

Champagne, F., A.P. Contandriopoulos, J.L. Denis, M. Gerbier, C. Poirier and L.H. Trottier. 2004. Les Enjeux du développement de la médecine académique. Rapport R04-03. Montréal: Groupe de recherche interdisciplinaire en santé. Retrieved December 17, 2008. <http://www.gris.umontreal. ca/rapportpdf/R04-03.pdf $>$.

Clair, M. 2000. Les Solutions émergentes: rapport et recommandations. Commission d'enquête sur les services de santé et de bien-être. Ottawa: Gouvernement du Canada.

Colin, C. 2004. "La Santé publique au Québec à l'aube du XXe siècle." Santé publique 16: 185-95.

Collins, F.S. 1999. "Medical and Societal Consequences of the Human Genome Project." New England Journal of Medicine 341: 28-37. Retrieved December 17, 2008. <http://content.nejm. org/cgi/content/full/341/1/28>.

Contandriopoulos, A.P. 1999."La Santé entre les sciences de la vie et les sciences sociales." Rupture 6: 174-91.

Contandriopoulos, A.P. 2003. "Inertie et changement." Rupture 9(2): 4-31.

Contandriopoulos, A.P., G. de Pouvourville, J.P. Poullier and D. Contandriopoulos. 2000. "À la recherche d'une troisième voie : les systèmes de santé au XXIe siècle." In M.P. Pomey, B. Lejeune and J.M. Poullier, eds., Santé publique (pp. 637-67). Paris: Éditions Ellipses.

Derose, S. and D. Petitti. 2003. "Measuring Quality of Care and Performance from a Population Health Care Perspective." Annual Review of Public Health 24: 363-84.

Donabedian, A. 1976. Aspects of Medical Care Administration: Specifying Requirements for Healthcare. Cambridge, UK: Harvard University Press.

Evans, R. 1999. "Regard sur l'avenir : les inégalités sociales en matière de santé." Horizons, projet de recherche sur les politiques $2(3): 6-7$.

Evans, R. and G. Stoddart. 1990. "Producing Health, Consuming Health Care." Social Science and Medicine 31: 1347-63.

Feachem, R., N. Sekhri and K. White. 2002. "Getting More for Their Dollar: A Comparison of the NHS with California's Kaiser Permanente." British Medical Journal 324: 135-41. 
Garr, D., R. Rhyne and G. Kukulka. 1993."Incorporating a Community-Oriented Approach in Primary Care." American Family Physician 47: 1699-702.

Glouberman, S. and J. Millar. 2003. "Evolution of the Determinants of Health, Health Policy, and Health Information Systems in Canada." American Journal of Public Health 93: 388-92.

Glouberman, S. and H. Minzberg. 2002. "Gérer les soins de santé et le traitement de la maladie." Gestion 27(3).

Gouvernement du Québec. 2003. An Act Respecting Local Health and Social Services Network Development Agencies. Québec: Assemblée nationale.

Ham, C., N. York, S. Sutch and R. Shaw. 2003. "Hospital Bed Utilisation in the NHS, Kaiser Permanente, and the US Medicare Programme: Analysis of Routine Data." British Medical Journal 327: $1257-62$.

Katzmarzyk, P., N. Gledhill and R. Shephard. 2000."The Economic Burden of Physical Inactivity in Canada." Canadian Medical Association Journal 163: 1435-40.

Kirby, M.J.L. 2002. The Health of Canadians - The Federal Role. Final Report. Volume Six. Ottawa: Standing Senate Committee on Social Affairs, Science and Technology.

Kizer, K., J. Demakis and J. Feussner. 2000."Reinventing VA Health Care: Systematizing Quality Improvement and Quality Innovation." Medical Care 38(6 Suppl. 1): I7-16.

Klein-Geltink, J., B. Choi and R. Fry. 2006. "Multiple Exposures to Smoking, Alcohol, Physical Inactivity and Overweight: Prevalences According to the Canadian Community Health Survey Cycle 1.1." Chronic Diseases in Canada 27(1): 25-33.

Lamarche, P., M.D. Beaulieu, R. Pineault, A.P. Contandriopoulos, J.L. Denis and J. Haggerty. 2003. Choices for Change: The Path for Restructuring Primary Healthcare Services in Canada. Ottawa: Canadian Health Services Research Foundation.

Lévesque, J.F. and P. Bergeron. 2003a. "De l'individuel au collectif : une vision décloisonnée de la santé publique et des soins." Rupture 9(2): 73-89.

Lévesque, J.F., R. Pineault, B. Simard, D. Roberge, M. Hamel, C. Kapetanakis et al. 2007a. L'Expérience de soins de la population: portrait des variations intra-régionales à Montréal et Montérégie. Montréal: Institut national de santé publique du Québec.

Lévesque, J.F., D. Roberge and R. Pineault. 2007b. "La Première ligne de soins : un témoin distant des réformes institutionnelles et hospitalières au Québec ?” In M.-J. Fleury, M. Tremblay, H. Nguyen and L. Bordeleau, eds., Le Système socio-sanitaire au Québec (pp. 63-78). Montréal: Gaëtan Morin.

Marmot, M., C. Ryff, L. Bumpass, M. Shipley and N. Marks. 1997. "Social Inequalities in Health: Next Questions and Converging Evidence." Social Science and Medicine 44: 901-10.

McKeown, T. 1979. The Role of Medicine: Dream, Mirage or Nemesis? Oxford, UK: Basil Blackwell.

McMichael, A. and R. Beaglehole. 2000."The Changing Global Context of Public Health." Lancet 2000: 495-99.

Ministère de la santé et des services sociaux. 2003. Québec Public Health Program 2003-2012. Québec: Author. Retrieved December 17, 2008. <http://publications.msss.gouv.qc.ca/acrobat/f/ documentation/2003/03-216-02A.pdf>. 
Ministry of Social Affairs and Health Finland. 2004. Healthcare in Finland. Brochure no. 11. Helsinki: Ministry of Social Affairs and Health.

Murray, C.J.L. and J. Frenk. 2000."A Framework for Assessing the Performance of Health Systems." Bulletin of the World Health Organization 78: 717-31.

Ohinmaa, A., D. Schopflocher, J.P, S. Demeter, A. Chuck, K. Golmohammadi and S.W.

Klarenbach. 2006. "A Population-Based Analysis of Health Behaviours, Chronic Diseases and Associated Costs." Chronic Diseases in Canada 27(1): 17-24.

Perlin, J., R. Kolodner and R. Roswell. 2005."The Veterans Health Administration: Quality, Value, Accountability and Information as Transforming Strategies for Patient-Centered Care." Healthcare Papers 5(4): 10-24.

Pineault, R. 1984. “The Place of Prevention in the Quebec Healthcare System." Canadian Journal of Public Health 75(1): 92-97.

Pineault, R., B. Baskerville and D. Letouzé. 1990. "Health Promotion Activities in Quebec Hospitals: A Comparison of DSC and Non-DSC Hospitals." Canadian Journal of Public Health 81(3): 199-203.

Pineault, R., F. Champagne and L.H. Trottier. 1986."The Integration of Public Health in Hospitals: The Case of Community Health Departments in Quebec." Journal of Public Health Policy 7: 458-62.

Pineault, R. and C. Daveluy. 1995. La Planification de la santé. Montréal: Éditions Nouvelles.

Pineault, R. and R. Lessard. 1984."Le Système de santé du Québec : objectifs de soins ou objectifs de santé ?” L'Union médicale du Canada 113: 750-55.

Pineault, R., J.-F. Lévesque, D. Roberge, M. Hamel, P. Lamarche and J. Haggerty. 2008. Accessibility and Continuity of Care: A Study of Primary Care Services in Québec. Research Report. Direction de santé publique de l'Agence de la santé et des services sociaux de Montréal, Institut national de santé publique du Québec et Centre de recherche de l'Hôpital Charles LeMoyne.

Public Health Agency of Canada (PHAC). 2005. Health Is Everyone's Business. Retrieved December 17, 2008. <http://www.phac-aspc.gc.ca/ph-sp/collab/index-eng.php >.

Richard, L., É. Breton, P. Lehoux, C. Martin and D. Roy. 1999. “La Perception des professionnels de santé publique face à deux dimensions de la promotion de la santé : approche écologique et participation." Canadian Journal of Public Health 90(2): 99-103.

Romanow, R.J. 2002. Building on Values: The Future of Health Care in Canada. Final Report. Saskatoon: Commission on the Future of Health Care in Canada. Retrieved December 17, 2008. <http://www.hc-sc.gc.ca/hcs-sss/alt_formats/hpb-dgps/pdf/hhr/romanow-eng.pdf>.

Rose, G. 1985. “Sick Individuals and Sick Populations.” International Journal of Epidemiology 30: 32-39.

Sicard, D. 2004. "Réflexion sur le progrès de la médecine." Médecine et bygiène 2401: 1535-38.

Starfield, B., K. Lemke, T. Bernhardt, S. Foldes, C. Forrest and J. Weiner. 2003. “Comorbidity: Implications for the Importance of Primary Care in 'Case' Management." Annals of Family Medicine $1(1): 8-14$.

Turgeon, J., A. Hervé and J. Gauthier. 2003. "L'Évolution du ministère et du réseau : continuité ou rupture ?" In V. Lemieux, P. Bergeron, C. Bégin and G. Bélanger, eds., Le Système de santé au Québec : organisations, acteurs et enjeux (pp.93-118). Québec: Les Presses de l'Université Laval. 
World Health Organization (WHO). 1986. The Ottawa Charter for Health Promotion. Ottawa: Author.

World Health Organization (WHO). 2005. Integrated Chronic Disease Prevention and Control. Geneva: Author. Retrieved December 17, 2008. <http://www.who.int/chp/about/integrated_cd/ en $/>$. 